\title{
O CURRÍCULO PARA A FORMAČÃO DO FISIOTERAPEUTA E SUA CONSTRUÇÃO HISTÓRICA
}

\author{
THE CURRICULUM FOR THE ACADEMIC TRAINING OF THE \\ PHYSICAL THERAPIST AND ITS HISTORIC CONSTRUCTION
}

\author{
Renato da Costa Teixeira \\ José Wagner Cavalcante Muniz \\ Curso de Fisioterapia \\ Universidade do Estado do Pará \\ Daniela Lobato Nazaré \\ Curso de Fisioterapia \\ Faculdade Maurício de Nassau
}

\author{
Contato \\ Renato da Costa Teixeira \\ Travessa Lomas Valentinas, 1.354 - Apto. 501 \\ Marco, Belém-PA \\ CEP: 66087-441 \\ E-mail: teixeirarenato@globo.com
}

\section{RESUMO}

O propósito deste estudo foi fazer uma revisão acerca da evolução dos currículos de Fisioterapia adotados no Brasil, para analisar os três currículos oficiais prescritos para os cursos de Fisioterapia à luz do que afirma a literatura. Para isso, utilizou-se a análise documental dos currículos oficiais, bem como documentos que serviram de base para esses currículos e de obras atuais sobre o tema. Etimologicamente, currículo representa um caminho a ser seguido por alguém e sempre é parte de uma seleção feita por um grupo dominante que decide qual deve ser o conhecimento ensinável determinado por contextos políticos e socioeconômicos. Recentemente o termo currículo mínimo, que representava uma lista de matérias que os cursos de graduação deveriam oferecer independentemente da região do país, foi substituído pelas Diretrizes Cur- riculares Nacionais (DCN). Estas, ao contrário de uma lista de matérias, propõem conteúdos essenciais, dando maior liberdade às Instituições de Ensino Superior. No caso da Fisioterapia, as DCN afirmam que o perfil profissional deve ser "generalista, humanista, crítico e reflexivo", deve possuir competências gerais comuns a todos os cursos da saúde e específicos da profissão, e os conteúdos essenciais devem envolver conhecimentos sociais e humanos, biológicos e da saúde, biotecnológicos e fisioterapêuticos. Este perfil não é exclusivo dessa classe, mas constam nas DCN de todas as profissões de saúde, dando a impressão de que exista a visão de algum grupo acerca do que deva ser ensinado. No entanto, para atingir plenamente os princípios e diretrizes do SUS, é necessário que todos sejam formados com a mesma visão.

Palavras-chave: Fisioterapia. Currículo. Ensino superior. 


\section{ABSTRACT}

The purpose of this study was to carry out a review about the evolution of physical therapy curricula adopted in Brazil, to analyze the three official curricula prescribed for physical therapy courses in light of literature. For that, we use the documental analysis of these official curricula, as well as official documents which serve as basis of such curricula and current works on the subject. Etymologically, the curriculum represents a path to be followed by someone and it is always part of a selection made by a dominant group that decides what should be teachable knowledge determined by political and socio- economic contexts. Recently, the National Curriculum Guidelines (NCGs) replaced the term minimum curriculum, representing a list of materials that undergraduate courses should offer inde- pendently of the region of the country. These, unlike a list of materials, propose essential content, giving more freedom for Higher Education Institutions. In the case of physical therapy, the claim that NCGs professional profile should be "generalist, humanist, critical and reflective" must have general competences like all health courses and specific of physical therapy, and the essential contents must involve social and human, biological and health, biotechnological and physiotherapeutic knowledge. That profile is not exclusive of this class, but are contained in NCGs of all health professions, giving the impression that there is a group's vision of what should be taught. However, to fully achieve the principles and guidelines of the NHS, it necessary that all are formed with the same vision.

Keywords: Physical therapy specialty. Curriculum. Education, Higher.

\section{DOS CURRÍCULOS MÍNIMOS ÀS DIRETRIZES CURRICULARES NACIONAIS}

\begin{abstract}
A formação de profissionais de saúde, a partir da perspectiva de integração dos vários níveis de atenção, [...] baseia-se principalmente na perspectiva de que a atenção à saúde deixa de ser vista como meramente curativa, individual e isolada do contexto social; ela ultrapassa a percepção da atenção básica (ou primária) como executora de ações que se restringem a evitar doenças (prevenção primária), tornando-se investigativa e promotora de melhores condições de qualidade de vida da sociedade como um todo (Ronzani) $^{1}$
\end{abstract}

$\triangle{ }^{a}$ companhando o movimento de mudança que aconteceu no modelo de atenção à saúde a partir da reforma sanitária desencadeada na década de 1980, os fisioterapeutas saíram das práticas reabilitadoras em que por muito tempo foram formados, para atuar em todos os níveis de atenção à saúde por meio dos Núcleos de Apoio à Saúde da Família (NASF), criados em 2008 pela Portaria $n^{\circ}$ $154 / G M / M S$, de 24 de janeiro de 2008, e, posteriormente, regulamentados pela Portaria $n^{\circ} 2488 / G M /$ MS, de 21 de outubro de 2011. Para acompanhar essa mudança, os cursos de graduação em Fisioterapia tiveram que adequar seus currículos.

Os estudos sobre o Currículo vêm ganhando espaço nas discussões, sofrendo uma diversificação das influências teóricas, a partir de 1970, produzindo-se com regularidade crescentes produções científicas acerca do tema².
O termo currículo foi utilizado pela primeira vez na penúltima década do século $\mathrm{XVI}$, na Universidade de Leiden (Holanda), e em Glasgow (Escócia), representando um conjunto de assuntos estudados pelos alunos ao longo do curso, surgindo na transição da Idade Média para a modernidade ${ }^{3}$. Na língua portuguesa, foi usada pela primeira vez em 1899 por Candido de Figueiredo no Novo Dicionário da Língua Portuguesa em Lisboa 4 .

Um dos marcos significativos da discussão sobre o Currículo teve início no ano de 1918 nos EUA com o lançamento da obra de Bobbitt intitulada The Curriculum5. Diferentes forças econômicas, políticas e culturais procuravam moldar os objetivos da educação de massa e, de acordo com suas visões, traziam à tona uma dúvida sobre formar um trabalhador especializado ou proporcionar uma educação geral e acadêmica à população $0^{5 ; 6}$.

Tradicionalmente, o conceito de Currículo limitava-se a uma lista de conteúdos que deveriam ser ministrados nas escolas. Somente na década de 1960 essa lista foi mais bem compreendida, e o porquê de por tanto tempo o currículo ter sido definido como algo estático que deveria ser seguido sem questionamentos. Assim, Michel Apple, explicita que:

O Currículo nunca é simplesmente uma montagem neutra de conhecimentos, que de alguma forma aparece nos livros e nas salas de aula de um país. Sempre parte de uma tradição seletiva, da seleção feita por alguém, da visão que algum grupo tem do que seja o conhecimento legítimo. Ele é produzido pelos conflitos, tensões e compromissos culturais, políticos e econômicos que organizam e desorganizam um povo ${ }^{7}$. 
No Brasil, o primeiro número da Revista Brasileira de Estudos Pedagógicos, de 1944, continha um artigo intitulado "Programa Mínimo", que enfatizava a importância da elaboração de currículos e programas que considerassem as necessidades sociais e as capacidades individuais ${ }^{8}$. O primeiro livro-texto sobre currículo no Brasil se intitulava "Introdução ao estudo do currículo na escola primária", publicado em 1955 pela Editora do INEP9 .

Currículo traz a ideia de caminho, percurso e significaria o caminho a ser percorrido pelo aluno. Esse caminho é parte de uma seleção feita por alguém ou da visão de algum grupo acerca do que deva ser ensinado ${ }^{10}$. A respeito disso, Kramer afirma:

Uma proposta pedagógica (ou curricular) expressa sempre os valores que a constituem, e precisa estar intimamente ligada à realidade a que se dirige, explicitando seus objetivos de pensar criticamente esta realidade, enfrentando seus mais agudos problemas ${ }^{11}$.

O currículo tem sido tomado como normas legais e documentos prescritivos determinados por contextos sociopolíticos e econômicos ${ }^{12 ; 13}$. Ele também pode designar não somente aquilo que é formalmente prescrito no programa, mas aquilo que é realmente ensinado nas salas de aula. Forquin se interroga a respeito do que acontece no interior das salas de aula, nas interações entre professores e alunos, o que o leva a diferenciar entre o que é prescrito oficialmente (o que ele chama de currículo formal) e aquilo que é aprendido pelos alunos (currículo aprendido), que não corresponde, necessariamente, àquilo que os docentes ensinam ou creem ensinar (currículo ensinado) ${ }^{14}$.

Perrenoud tem uma visão semelhante à de Forquin ao afirmar que o processo que ocorre nas escolas, a fim de que os saberes sejam ensináveis, acontece em três fases: fase do currículo formal (programas, metodologias e meios de ensino), fase do currículo real (processo em que os saberes a ensinar são transformados em ensinados) e fase em que os saberes ensinados são adquiridos pelos alunos ${ }^{15}$.

Pela antiga Lei de Diretrizes e Bases da Educação Nacional, competia ao Conselho Federal de Educação estabelecer a duração e o currículo mínimo dos cursos de ensino superior ${ }^{16}$.

Em 1995, a Lei $n^{\circ}$ 9.131, de 24 de novembro de 1985, introduziu alterações na legislação substituindo os currículos mínimos pelas Diretrizes Curriculares Nacionais $(\mathrm{DCN})^{17}$.

Em 1996, com a edição da Lei $n^{\circ}$ 9.394, de 20 de dezembro de 1996, Lei de Diretrizes e Bases da
Educação Nacional (LDB), as Instituições de Ensino Superior (IES) ganharam maior grau de autonomia na elaboração curricular, o que possibilitou o desenho de currículos mais adequados às realidades regionais. Segundo Rocha, essa LDB estabeleceu como eixo orientador para o ensino superior as diretrizes curriculares dos cursos de graduação ${ }^{18}$.

O processo para elaboração das diretrizes curriculares foi desencadeado pela Câmara de Educação Superior (CES), com a designação de uma comissão para aprovação de diretrizes gerais que servissem de base para as comissões de especialistas elaborarem as DCN ${ }^{19}$.

Especificamente em relação à Fisioterapia, achamos conveniente conhecer como se deu a construção histórica de seus currículos até o advento das DCN.

\section{DOS PRIMEIROS CURSOS DE FISIOTERAPIA ȦS DCN}

\section{a) De 1950 a 1964 - os primeiros cursos: a formação de Técnicos em Fisioterapia}

A utilização dos recursos físicos como terapia surgiu no Brasil já no século XIX, em serviços localizados nas cidades de São Paulo e Rio de Janeiro, sendo chamados na época de "eletricidade médica". Em 1929, o médico Dr. Waldo Rolim de Moraes instalou o serviço de fisioterapia do Instituto Radium Arnaldo Vieira para atender a pacientes da Santa Casa de Misericórdia de São Paulo. Posteriormente, organizou o serviço de fisioterapia do Hospital das Clínicas de São Paulo. Iniciativa semelhante ocorreu no Rio de Janeiro, em 1945, com a inauguração do Hospital Municipal Barata Ribeiro que contava com um serviço de eletromedicina ${ }^{20}$.

Apesar disso, a criação dos primeiros cursos para formação de técnicos em fisioterapia no Brasil ocorreu somente na década de 1950, também em São Paulo e Rio de Janeiro. O primeiro curso foi realizado em São Paulo pelo Centro de Estudos Raphael de Barros, com duração de um ano, e manteve suas atividades até 1957 . Neste ano, com a criação do Instituto Nacional de Reabilitação (INAR), foi oferecido outro curso com dois anos de duração, absorvendo como professores os técnicos formados pelo antigo curso e que trabalhavam no serviço ${ }^{21}$.

No Rio de Janeiro, um grupo de médicos do Hospital Jesus, atual Hospital de Traumato-Ortopedia (Osvaldo Pinheiro de Campos, Jorge Affonseca de Barros Faria e Antonio Caio do Amaral), criaram um curso para formação de técnicos em reabilitação, para atuar na recém-criada Associação Brasileira Beneficente de Reabilitação (ABBR), tendo sua primeira turma colado grau em $1958^{22}$. 
Os cursos localizados em São Paulo e no Rio de Janeiro funcionavam como cursos independentes, isto é, desvinculados de instituições de ensino, e tinham apenas o objetivo de formar pessoal qualificado para auxiliar os médicos no processo de reabilitação, tanto de crianças vítimas da epidemia de poliomielite quanto de soldados que haviam voltado da Segunda Guerra Mundial, como também pessoas acometidas por acidentes de trabalho, problema que apresentava um dos maiores índices da América do Sul.

Oliveira, ao estudar o histórico dos currículos de fisioterapia no Brasil, informa que havia currículos próprios, necessitando, para ingresso, apenas o término do ginasial (correspondente hoje ao ensino fundamental). Portanto, "não obedeciam a uma normatização nacional, e não possuíam estrutura curricular mínima que direcionasse a formação do novo profissional ainda tão pouco conhecido"8.

Segundo a autora, esses dois cursos possuíam currículos diferentes, garantindo apenas uma qualificação técnica, sem a intenção de proporcionar uma formação ampla ao profissional, e obedeciam a uma lista de conteúdos de acordo com a necessidade do serviço, uma vez que até esse momento não existiam normas governamentais para esse curso.

Essa situação foi mantida até 1964, quando, em 23 de julho, foi promulgada a Portaria Ministerial $n^{\circ}$ $511 / 64$, que estabeleceu o mínimo de conteúdo e duração dos cursos de Fisioterapia e Terapia Ocupacional.

\section{b) De 1964 a 1983 - o primeiro currículo: a formação de Técnicos de Nível Superior (ou fisioterapistas)}

O curso de São Paulo formou os primeiros fisioterapistas (denominação da época). Era mantido pelo Centro de Estudos Raphael de Barros, que levava este nome em homenagem ao professor de física biológica da Faculdade de Medicina, que criou o departamento de eletricidade médica na Faculdade de Medicina da Universidade de São Paulo em $1919^{20}$.

A formação técnica nesses cursos era tão clara que, no Parecer 388/63 do Conselho Federal de Educação (Parecer da comissão composta pelo Ministério da Educação para estabelecer as bases e diretrizes para o funcionamento dos profissionais em Reabilitação no Brasil com cinco integrantes, todos médicos, e que viria a dar sustentação ao processo de reconhecimento dos cursos já existentes), o fisioterapeuta foi definido como auxiliar médico, estabelecendo que competia a esse profissional apenas a realização de tarefas de caráter terapêutico precedidas por uma prescrição médica ${ }^{21}$.
Esse Parecer serviu de base para Portaria Ministerial 511/64 que estabelecia, em apenas dois artigos, o conteúdo mínimo e o tempo de duração dos cursos de Fisioterapia. Essa proposta era no sentido de um curso com duração prevista para três anos e destinada à formação de técnicos em Fisioterapia. Estabelecia um currículo visando à formação de um perfil profissional técnico na perspectiva de cursos em nível médio. $\mathrm{O}$ art. $1^{\circ}$ estabelecia as cinco matérias a serem cursadas: Fundamentos de Fisioterapia; Ética e História da Reabilitação; Administração aplicada; Fisioterapia Geral e Fisioterapia Aplicada. $\mathrm{O}$ art. $2^{\circ}$ estabelecia o tempo de duração do curso em três anos.

Estava embasado em uma visão de mundo cartesiana e mecanicista, em um sistema de grades curriculares fechadas e inflexíveis, nas quais o que importava era meramente a transmissão do conhecimento das habilidades técnicas ${ }^{23}$.

Em 1959, foi fundada, em São Paulo, a Associação Brasileira de Fisioterapia, que veio a desempenhar um papel importante na transformação do curso de nível técnico para nível superior ${ }^{8}$.

No entanto, apenas em 1969, após grande articulação da Associação Brasileira de Fisioterapia com a Junta Governativa formada pelo Ministro do Exército, Ministro da Marinha e Ministro da Aeronáutica, foi editado o Decreto-Lei 938, de 13 de outubro de 1969, reconhecendo o fisioterapeuta como profissional de nível superior, com autonomia para o exercício profissional.

Apesar desse reconhecimento, o currículo mínimo criado em 1964 para formação dos fisioterapeutas técnicos permaneceria o mesmo até 1983, quando o Conselho Federal de Educação estabeleceu um novo Currículo Mínimo para os cursos de graduação em Fisioterapia, ou seja, de 1969 a 1983, tivemos um período de 14 anos formando fisioterapeutas com formação técnica para o exercício de uma profissão de nível superior.

\section{c) De 1983 a 2002 - o segundo currículo: a formação de fisioterapeutas}

Em 1983, com a assessoria da Associação Brasileira de Fisioterapeutas, foi publicada, pelo Conselho Federal de Educação, a Resolução 04/83, criando o segundo Currículo Mínimo para os cursos de graduação em fisioterapia, estabelecendo uma duração mínima de quatro anos24. Esta possuía 11 artigos e compreendia 4 ciclos de aprendizado: I. Matérias Biológicas; II. Matérias de Formação Geral; III. Matérias Pré-profissionalizantes e IV. Matérias Profissionalizantes.

O ciclo de Matérias Biológicas constava das seguintes matérias: Biologia; Ciências Morfológicas 
(Anatomia Humana e Histologia); Ciências Fisiológicas (Bioquímica, Fisiologia e Biofísica) e Patologia (Patologia Geral e Patologia de Órgãos e Sistemas).

O ciclo de Matérias de Formação Geral constava das seguintes matérias: Ciências do Comportamento (Sociologia, Antropologia, Psicologia, Ética e Deontologia); Introdução à Saúde Humana (Saúde Pública) e Metodologia de Pesquisa Científica (incluindo Estatística).

O ciclo de Matérias Pré-Profissionalizantes constava de: Fundamentos de Fisioterapia (História da Fisioterapia e Administração em Fisioterapia); Avaliação Funcional (Cinesiologia, Bases de Métodos e Técnicas de Avaliação em Fisioterapia); Fisioterapia Geral (Eletroterapia, Termoterapia, Fototerapia, Hidroterapia e Mecanoterapia); Cinesioterapia (Exercício Terapêutico e Reeducação Funcional) e Recursos Terapêuticos Manuais (Massoterapia e Manipulação).

O ciclo de Matérias Profissionalizantes constava de: Fisioterapia aplicada às condições neuromusculoesqueléticas (Fisioterapia aplicada a Ortopedia e Traumatologia, à Neurologia e à Reumatologia); Fisioterapia aplicada às condições cardiopulmonares (Fisioterapia aplicada à Cardiologia e Pneumologia); Fisioterapia aplicada às condições gineco-obstétricas e pediátricas (Fisioterapia aplicada à Ginecologia e à Obstetrícia e Fisioterapia aplicada à Pediatria); Fisioterapia aplicada às condições sanitárias (incluindo Fisioterapia Preventiva) e Estágio Supervisionado.

Esse currículo, consolidou esse profissional com um perfil tecnicista, na perspectiva da formação profissional baseada principalmente no conhecimento das técnicas de tratamento e voltado para as especialidades, uma vez que, à época, era dada pouca importância à formação social e humana do profissional de saúde e em especial do fisioterapeuta.

$\mathrm{O}$ art. $9^{\circ}$ dessa resolução estabelecia que os ciclos I e II (Matérias Biológicas e de Formação Geral) deveriam ocupar apenas $20 \%$ do total da carga horária do curso, os demais $80 \%$ eram distribuídos entre o Ciclo Pré-profissionalizante (20\%), Profissionalizante (40\%) e Estágio Curricular (20\%).

Essa Resolução perdurou durante 19 anos, quando então, em 2002, foram editadas as DCN para os cursos de Graduação em Fisioterapia. Nesse período, o Conselho Federal Fisioterapia e Terapia Ocupacional editou três Resoluções reconhecendo as especialidades de Fisioterapia Pneunmofuncional (Resolução $n^{\circ}$. 188, de 9 de dezembro de 1998), Neurofuncional (Resolução $n^{\circ}$. 189, de 9 de dezembro de 1998) e Acupuntura (Resolução n. 219, de 14 de dezembro de 2000), fortalecendo a consolidação do fisioterapeuta especialista adotada pelo currículo mínimo.

\section{d) A partir de 2002 - com as DCN: a formação do novo fisioterapeuta}

A Resolução 04/83 vigorou até 2002, quando foram aprovadas as DCN do Curso de Graduação em Fisioterapia (DCN/FISIO), por meio da Resolução CNE/ CES 04, de 19 de fevereiro de 2002, e que definiram os princípios, fundamentos, condições e procedimentos da formação de fisioterapeutas ${ }^{25}$. As DCN/FISIO possuem 15 artigos e foram aprovadas após consulta pública da qual participaram com sugestões, além do Conselho Federal de Fisioterapia e Terapia Ocupacional, a Associação Brasileira de Ensino em Fisioterapia que realizou diversos fóruns de discussão com participação maciça de professores de diversas regiões do país.

O Parecer CNE/CES 583/2001 definiu que as diretrizes deveriam contemplar: a) perfil do formado / egresso / profissional; b) competências / habilidades / atitudes; c) habilitação e ênfase (quando fosse o caso); d) conteúdos curriculares; e) organização do curso; f) estágios e atividades complementares e g) acompanhamento e avaliação ${ }^{26}$.

O Parecer CNE/CES 1.210/2001 adotou esse formato preconizado, para as áreas de conhecimento que integram a saúde nos cursos de Fisioterapia, Fonoaudiologia e Terapia Ocupacional, estabelecendo que era objeto das Diretrizes Curriculares:

"[...] permitir que os currículos propostos possam construir perfil acadêmico e profissional com competências, habilidades e conteúdos, dentro de perspectivas e abordagens contemporâneas de formação pertinentes e compatíveis com referências nacionais e internacionais, capazes de atuar com qualidade, eficiência e resolutividade, no Sistema Único de Saúde (SUS), considerando o processo da Reforma Sanitária Brasileira"29.

Ainda de acordo com esse Parecer, o objetivo das Diretrizes Curriculares era:

"[...] levar os alunos dos cursos de graduação em saúde a aprender a aprender que engloba aprender a ser, aprender a fazer, aprender a viver juntos e aprender a conhecer, garantindo a capacitação de profissionais com autonomia e discernimento para assegurar a integralidade da atenção e a qualidade e humanização do atendimento prestado aos indivíduos, famílias e comunidades"27. 
Assim, o art. $3^{\circ}$ das DCN/FISIO, que trata do perfil de formação profissional, afirma que o fisioterapeuta "[...] deve ter uma formação generalista, humanista, crítica e reflexiva, capacitado a atuar em todos os níveis de atenção à saúde, com base no rigor científico e intelectual"25.

O perfil aponta para um profissional apto a analisar os problemas da sociedade, tendo em conta que a responsabilidade da atenção à saúde não se encerra com o ato técnico, mas com a resolução do problema de saúde. Além disso, deve ser capaz de comprometer-se com o ser humano, reconhecendo a saúde como direito a condições dignas de vida, considerando as circunstâncias éticas, políticas, sociais, econômicas, ambientais, biológicas e culturais do indivíduo, exercendo sua profissão de forma articulada ao contexto social, entendendo-a como uma forma de participação e contribuição social ${ }^{25}$.

Os arts. $4^{\circ}$ e $5^{\circ}$ tratam dos conhecimentos requeridos para o exercício de competências e habilidades gerais e específicas respectivamente. $\mathrm{O}$ art. $4^{\circ}$ segue a mesma redação das $\mathrm{DCN}$ das 14 profissões da saúde e discorre sobre seis competências e habilidades gerais (Atenção a saúde, tomada de decisões, comunicação, liderança, administração e gerenciamento e educação permanente), enquanto $\mathrm{o}$ art. $5^{\mathrm{a}}$ discorre sobre 16 competências e habilidades específicas do fisioterapeuta.

De acordo com 0 art. $6^{\circ}$ dessa Resolução, os currículos dos cursos de Fisioterapia devem estar relacionados com todo o processo saúde-doença do cidadão, da família e da comunidade e devem contemplar conteúdos essenciais das Ciências Biológicas e da Saúde, das Ciências Sociais e Humanas, além dos Conhecimentos Biotecnológicos e Fisioterapêuticos.
$\mathrm{O}$ art. $7^{\circ} \mathrm{diz}$ respeito ao estágio curricular obrigatório sob supervisão docente com uma carga horária mínima de $20 \%$ da carga horaria total do curso incluindo intervenções preventivas e curativas nos diferentes níveis de atuação: ambulatorial, hospitalar, comunitário / unidades básicas de saúde.

Ressalta-se que as DCN estabelecem ainda que as atividades práticas específicas da Fisioterapia devem ser desenvolvidas gradualmente desde o início do Curso de Graduação em Fisioterapia, com complexidade crescente, e que para ser assegurada a formação generalista, os conteúdos curriculares devem ser diversificados, mas assegurando o conhecimento equilibrado de diferentes áreas, níveis de atuação.

$\mathrm{O}$ art. $8^{\circ}$ estabelece a necessidade de ser contemplado atividades complementares (monitorias e estágios; programas de iniciação científica; programas de extensão; estudos complementares e cursos realizados em outras áreas afins).

Os arts. $9^{\circ}$ e 10 tratam do projeto pedagógico do curso afirmando que este deve ser construído coletivamente, contribuindo para a compreensão, interpretação, preservação, reforço, fomento e difusão das culturas nacionais e regionais, internacionais e históricas, em um contexto de pluralismo e diversidade cultural.

Os arts. 11 e 12 discorrem sobre a organização do curso e da necessidade de um trabalho de conclusão de curso sob orientação docente.

Em relação aos currículos mínimos anteriores, as Diretrizes Curriculares têm um sentido muito mais amplo, buscando uma formação capaz de "assegurar a integralidade da atenção e a qualidade e humanização do atendimento prestado aos indivíduos, famílias e comunidades" conforme prescrito no Parecer 1.210 do CNE/CES. 


\title{
CONSIDERAC̣ÕES ACERCA DAS DCN/FISIO
}

\begin{abstract}
ntes da edição das DCN, já vinha sendo observado um aumento no número de cursos de graduação em fisioterapia no Brasil28, porém, após a edição das DCN, esse aumento foi expressivo e consequentemente provocou um incremento no número de vagas e de profissionais cadastrados no Conselho Federal de Fisioterapia e Terapia Ocupacional29, o que pode ser observado no gráfico abaixo.
\end{abstract}

Gráfico 1: Relação entre vagas ofertadas e número de fisioterapeutas cadastrados no sistema COFFITO 2004/2016

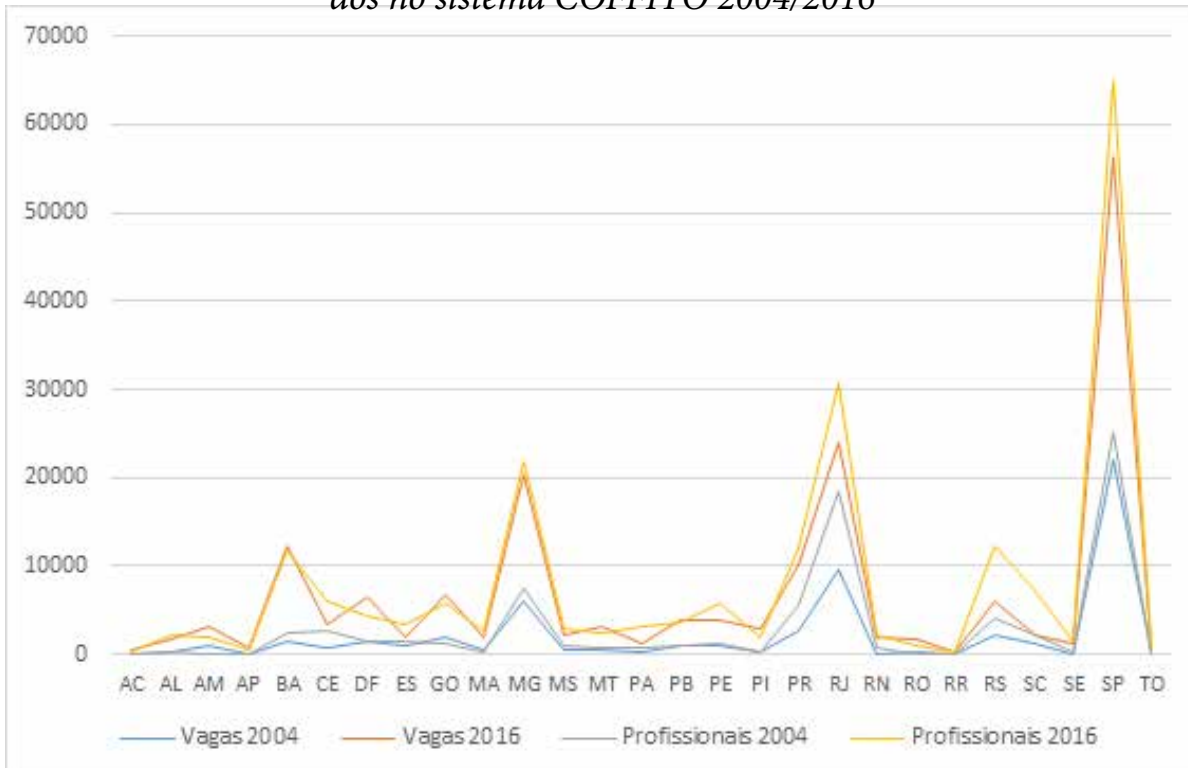

Fonte: COFFITO, 2016

Como se pode ver, esse aumento vem ocorrendo de forma mais acentuada nos estados de Minas Gerais, Rio de Janeiro e São Paulo. Diante disso, faz-se necessária uma discussão mais atenta sobre alguns termos/expressões que constam nas DCN, a fim de que gestores e docentes não tenham dúvidas a respeito do tipo de profissional que se quer formar. 


\section{QUANTO AO PERFIL GENERALISTA, HUMANISTA, CRITICO E REFLEXIVO}

A s diretrizes curriculares das profissões da área da saúde tiveram como referência a Constituição Federal de 1988, a Lei Orgânica do Sistema Único de Saúde, a Lei de Diretrizes e Bases da Educação Nacional, a Lei que aprovou o Plano Nacional de Educação, o Parecer CNE/CES 776/97, o Edital da SESu/MEC 4/97, o Parecer CNE/CES 583/2001, a Declaração Mundial sobre Educação Superior no Século XXI da Conferência Mundial sobre o Ensino Superior, o Relatório Final da $11^{\text {a }}$ Conferência Nacional de Saúde, o Plano Nacional de Graduação do ForGRAD de maio/1999, Documentos da OPAS, OMS e Rede UNIDA e os Instrumentos legais que regulamentam o exercício das profissões da saúde ${ }^{27}$.

Essa forma de ver a formação do profissional em saúde impôs a construção de matrizes curriculares menos técnicas e com maior equilíbrio entre os diversos conteúdos. Os generalistas são profissionais que incorporam em sua formação, além do conhecimento técnico, o da epidemiologia, da educação em saúde, do trabalho multidisciplinar, executando durante o processo de formação projetos que envolvam ações de prevenção e promoção da saúde tanto individual quanto coletivamente, havendo necessidade de um conhecimento mais global e menos específico ${ }^{30}$.

O generalista deve ser capaz de conhecer o indivíduo em sua integralidade, ou seja, no seu contexto familiar e social, buscando a solução dos principais problemas de saúde que ele apresenta, em sua subjetividade pessoal e em sua objetividade socioeconômica e cultural ${ }^{31}$.

Em oposição ao generalista, o especialista, que era fomentado na legislação anterior, é aquele que possui habilidades ou conhecimentos especiais em determinada prática ou ramo do saber ou que se especializou em determinado assunto ou atividade, tendo profundo conhecimento do que faz.

A formação de um especialista em saúde pressupõem o ensino baseado na doença, e não no processo de saúde, levando a uma qualificação precoce por meio de disciplinas especializadas. Em contrapartida, formar um generalista requer um currículo voltado para a coletividade, levando à produção de competências mediante conteúdos curriculares (Figura 1).
Figura 1: Formação do especialista versus formação do profissional generalista

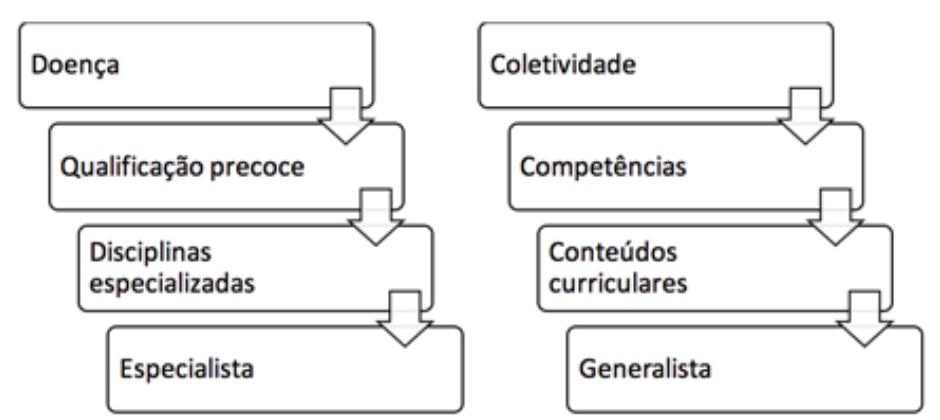


Em relação à formação humanista, é aquela que consegue congregar a pesquisa, o ensino, a extensão e a assistência, tendo como eixo de construção dessa formação a investigação científica e como referência a cidadania, tomando o homem como medida das coisas ${ }^{30}$.

O humanismo é um movimento filosófico-literário que tem como fundamento a matéria humana ${ }^{32}$. O seu aspecto fundamental é o reconhecimento do valor humano em sua totalidade e a tentativa de compreender o homem em seu mundo, que é o mundo natural com sua história, fazendo do homem a medida das coisas.

Carl Roger, psicólogo americano, destacou-se no desenvolvimento do humanismo na área da psicologia. Para ele, nas relações humanas, devemos visualizar a existência do sujeito como um processo contínuo de desenvolvimento e buscar resgatar o respeito pelo ser humano ${ }^{33}$.

Segundo Lima, Paulo Freire nos mostra que, em suas relações com o mundo, homens ou animais têm atitudes diferenciadas, defendendo que os homens não são objetos, mas sujeitos, embora possam, muitas vezes, ser tratados como objetos, isto é, "possam ser desumanizados" 34 .

Figura 2: Relação homem-mundo versus relação animal-mundo
Relação homem-mundo

a) Postura crítica

b) Pluralidade

c) Consequência

d) Transcendência
Relações animal-mundo

a) Ausência de postura crítica

b) Singularidade

c) Inconsequência

d) Imanência
Como pudemos observar, existem diferentes maneiras de ver a formação humanista, o que não ficou claro nas diretrizes de qual formação estava sendo exigida.

A formação generalista e humanista veio em razão da necessidade de entendermos a saúde não como uma mera ausência de doença, mas de compreendermos os fatores determinantes e condicionantes socioculturais (entre outros a alimentação, a moradia, o saneamento básico, o meio ambiente, o trabalho, a renda, a educação, o transporte, o lazer e o acesso aos bens e serviços essenciais) $)^{35}$.

Quanto à formação crítica e reflexiva, é aquela que leva o profissional a desenvolver suas atividades, preparando-o para tomar decisões, conhecendo suas limitações, buscando manter-se atualizado no conhe- cimento, adotando uma atitude questionadora, sendo um conhecedor do método científico para resolução de problemas, refletindo suas próprias ações ${ }^{30}$.

Em um ensaio com subsídios para formação de um profissional de saúde crítico-reflexivo, De Sordi e Bagnato nos mostram que o que determina se uma formação profissional se dá em um sentido progressista, crítico-reflexivo ou conservadora e tecnicista é o "modo de entender e fazer a educação, de como ela é trabalhada em sala de aula, espaço de interação entre professores e alunos", tornando assim o profissional mais humano ao entender o que se passa com o outro ${ }^{36}$.

Portanto, para conseguir uma formação humanista, crítica e reflexiva, não basta a inclusão de disciplinas, é necessário um docente com postura crítica e humanizada, pois, do contrário, formaremos um profissional acrítico e sem postura humanista.

\section{QUANTO ÀS COMPETÉNCIAS E HABILIDADES}

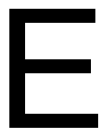
$m$ relação às competências gerais e específicas esperadas, é necessário conceituarmos inicialmente o termo competência. Para Perrenoud, pode ser entendida como "uma capacidade de agir eficazmente em um determinado tipo de situação, apoiada em conhecimentos, mas sem limitar-se a eles", sendo considerada a mais importante meta da formação ${ }^{37}$. Competência pode ser entendida como os conhecimentos, as habilidades e as atitudes que são mobilizados para a realização de uma ação específica ${ }^{38}$.

Assim, [para esse autor] não existem trabalhadores competentes a priori. $\mathrm{O}$ indivíduo só é considerado competente em uma situação real. As capacidades adquiridas pelo indivíduo em sua trajetória de vida são apenas recursos potenciais. Somente a situação real é capaz de evidenciar a competência profissional.

Dessa forma, Pimenta e Ghedin chamam a atenção que a formação profissional por competência requer a articulação de saberes diversos para a resolução de problemas e situações imprevistas em face dos desafios do trabalho ${ }^{39}$.

Competência tem sido definida como conhecimentos, habilidades e atitudes, ou seja, um conjunto de capacidades que justificam um desempenho superior, fundamentado na inteligência e personalidade das pessoas ${ }^{40}$. 
Dessa forma, os quatro pilares da educação defendidos por Delors e contido nos objetivos das Diretrizes Curriculares, de acordo com a Resolução 1.210 citada anteriormente, estão contemplados nesse conceito de competência, uma vez que engloba o conhecimento (aprender a conhecer), as habilidades (aprender a fazer) e as atitudes (aprender a ser e aprender a viver juntos $)^{41}$. (Figura 3)

Figura 3: Os quatro pilares da educação e as competências

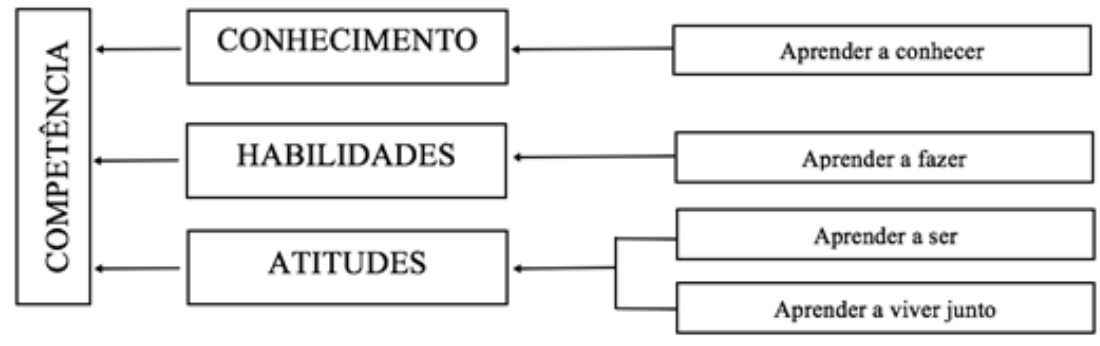

Para a formação de competências, é necessário um processo que expanda a educação formal, incluindo a experiência profissional e social (Quadro 1$)^{40}$.

Quadro 1: Processo de formação de competências segundo Le Boterf

Tipo de conhecimento

Teórico

Procedimentos

Empírico

Social

Cognitivo

\section{Função}

Entendimento, interpretação

Saber como proceder

Saber como fazer

Saber como se comportar

Saber como lidar com a informação

Saber como aprender
Forma de desenvolvimento

Educação formal e continuada

Educação formal e experiência profissional

Experiência profissional

Experiência social e profissional

Educação formal e continuada e experiência social e profissional 


\section{CONSIDERAÇÕES FINAIS}

$\mathrm{O}$ currículo para a formação do fisioterapeuta evoluiu em sua história de um modelo técnico que formava fisioterapistas, cujo papel era de auxiliar os médicos na reabilitação dos pacientes, passando por um modelo tecnicista, que formava fisioterapeutas - porém com uma visão restrita do homem e de sua atuação na saúde -, até chegar ao modelo atual com formação generalista e humanista em que assume a senhoridade científica e autonomia profissional para sua função na sociedade.

O novo perfil não é exclusivo dos fisioterapeutas, mas consta das $\mathrm{DCN}$ de todas as 14 profissões de saúde. Esse fato pode nos levar a questionar se por trás desse perfil de formação ainda continua existindo aquilo que Michael Apple afirmava ser "a visão de algum grupo acerca do que deva ser o conhecimento ensinável"".

A Constituição Federal, em seu art. 200, alínea III, dispõe, como uma das competências do SUS ordenar a formação de recursos humanos na área de saúde. Fortalecendo essa ideia, a Lei 8.080/90, que regulou as ações e serviços de saúde em todo território nacional, incluiu no campo de atuação do SUS essa ordenação, além de organizar um sistema de formação em todos os níveis de ensino, inclusive de pós-graduação.

Para que se possa atingir plenamente os princípios e diretrizes do SUS (universalidade, equidade, integralidade), é necessário que todos os profissio- nais que trabalham na saúde tenham uma formação voltada para essas diretrizes, o que nos faz compreender o perfil repetido por todas as 14 profissões.

Se no primeiro currículo para formação do fisioterapeuta a lista de conteúdos era ditada por outros profissionais, hoje, essa lista foi estabelecida pelos próprios fisioterapeutas, possibilitando pensar na atuação do fisioterapeuta, o que é necessário à sua formação, e escolher o que deve ser ensinado, dentro do contexto de saúde do Brasil.

As referências ao passado são indispensáveis para elucidarmos o contexto vivido, fornecendo significados para a cultura das profissões, dando uma consciência crítica e reflexiva aos profissionais42. Esperamos que, ao visitar o passado, o leitor possa, ao conhecer o caminho traçado para chegar ao modelo atual de formação do fisioterapeuta, ter condições de agir sobre a realidade da profissão, superando os problemas que se apresentarão na prática diária.

Acreditamos que uma diretriz ou currículo "ideal" seja aquele que tenha uma perfil demarcando as especificidades da fisioterapia, ampliando o olhar sobre a complexidade do fazer em saúde, com base em competências profissionais, com participação da comunidade em sua construção, com olhar para as necessidade da população e que seja flexível para permitir que cada instituição possa construir seu desenho curricular baseado em suas possibilidades, porém garantindo um mínimo de conhecimento necessário para atingir o perfil almejado. 


\section{Referências}

1. Ronzani TM. A reforma curricular nos cursos de saúde: qual o papel das crenças? Rev Bras Educ Med. 2007;31(1):38-43.

2. Moreira, AFB. A recente produção científica sobre currículo e multiculturalismo no Brasil (1995-2000): avanços, desafios e tensões. Ver Bras Educ. 2001;18:65-81.

3. Maia JA. O currículo no ensino superior em saúde. In Batista NA, Batista SH. Docência em saúde: temas e experiências. São Paulo: Senac Editora, 2003, p. 101-133

4. Houaiss A. Dicionário Eletrônico HOUAISS da língua portuguesa. São Paulo: Instituto Antônio Houaiss, 2002.

5. Silva TT. Documentos de identidade: uma introdução às teorias do currículo. 2. ed. Belo Horizonte: Autêntica, 2003.

6. Moreira AF, Silva TT (orgs.). Currículo, Sociedade e Cultura. São Paulo: Cortez, 1999.

7. Apple MW. Política Cultural e Educação. São Paulo: Cortez, 2000.

8. Oliveira VRC. A História dos Currículos de Fisioterapia: a construção de uma identidade profissional. [Dissertação]. Goiânia: Universidade Católica de Goiás; 2002.

9. Moreira AFB. Currículos e programas no Brasil. 3. ed. Campinas: Papirus, 1997.

10. Young M. A propósito de uma sociologia crítica da educação. Rev Bras Est Pedag. 1986;67(157):532-537.

11. Kramer S. Propostas pedagógicas ou curriculares: subsídios para uma leitura crítica. Educação e sociedade. Ano XVIII, nº 60, dezembro, 1997. p.15-35.

12. Macedo E. O que significa currículo disciplinar? In Candau V. Linguagens, espaços e tempos de ensinar e aprender. Encontro Nacional de Didática e Prática do Ensino (ENDIPE). Rio de Janeiro. DPA, 2000, p. 131-148.

13. Goodson I. Dar voz ao professor: a história de vida do professor e o seu desenvolvimento profissional. In: Novoa A (Org.) Vidas de professores. Porto: Porto Editora, 1992, p. 63-78.

14. Forquin JC. Escola e Cultura: a bases sociais e epistemológicas do conhecimento escolar. Artes Médicas: Porto Alegre, 1993, 208p.

15. Fernandes $C$. Interações de propostas curriculares oficiais e não-oficiais no espaço escolar e suas implicações para a prática curricular de uma escola pública/ resultados de pesquisa. $23^{a}$ Reunião da Associação Nacional de Pós-graduação e pesquisa em Educação - ANPED (GT 13 - Educação Fundamental). 24 a 28 de setembro de 2000. Caxambu. 2000.

Disponível em: http://189.1.169.50/reunioes/23/textos/1306t.PDF. Acessado em: 18 dez 2007.

16. Brasil. Lei 4024 de 20 de dezembro de 1961. Fixa as Diretrizes e Bases da Educação Nacional. Diário Oficial [da] República Federativa do Brasil. Poder Executivo. Brasília, DF, 27 dez 1961, p. 11429

17. Brasil. Lei $n^{\circ} 9131$ de 24 de novembro de 1995. Altera dispositivos da Lei n 4.024, de 20 de dezembro de 1961, e dá outras providências. Diário Oficial [da] União. Poder Executivo. Brasília, DF, 25 nov 1995, Edição Extra.

18. Rocha VR et al. As Diretrizes Curriculares e as mudanças na formação de profissionais fisioterapeutas. XVI Fórum Nacional de Ensino em Fisioterapia da ABENFISIO. Documento. Associação Brasileira de Ensino de Fisioterapia. ABENFISIO. Canela/RS. 07 a 09 de junho, 2007.

19. Frauches CC (Org). Diretrizes Curriculares para os cursos de graduação. Brasília: ABMES Editora. 2008, 702p.

20. Marques AP, Sanches EL. Origem e evolução da Fisioterapia: aspectos históricos e legais. Rev Fisio. 1994;1(1):5-10.

21. Barros FBM. Da visão romântica aos conflitos, fechamento e exclusão na área de saúde. Revista Fisiobrasil. 2004;68(8):36-38.

22. Moura Filho AG. Brasil: a Fisioterapia e o Tempo. (Texto produzido para leitura no Congresso Brasileiro de Fisioterapia). Salvador, 1999.

23. Teixeira CB. Diretrizes Curriculares Nacionais de graduação em Fisioterapia: O perfil do fisioterapeuta. [Dissertação]. Curitiba: Universidade Tuiuti; 2004. 
24. Brasil. Ministério da Educação. Resolução $n^{\circ}$ 4, de 28 de fevereiro de 1983. Fixa os mínimos de conteúdo e duração dos cursos de Fisioterapia e Terapia Ocupacional. Relator: Lafayette de Azevedo Ponde. Revista Documenta. Brasília, n. 268, p.191-192, abr. 1983.

25. Brasil. Conselho Nacional de Educação. Câmara de Educação Superior Resolução $n^{\circ} 4$ de 19 de fevereiro de 2002. Institui as Diretrizes Curriculares Nacionais do curso de graduação em Fisioterapia. Brasília, DF. Março 2002, 5p.

26. Brasil. Conselho Nacional de Educação. Câmara de Educação Superior. Parecer CNE/CES 583/2001. Orientação para as diretrizes curriculares dos cursos de graduação. Brasília, DF. Diário Oficial da União de 29 Out 2001.

27. Brasil. Conselho Nacional de Educação. Câmara de Educação Superior. Parecer CNE/CES 1.210/2001. Diretrizes Curriculares Nacionais dos Cursos de Graduação em Fisioterapia, Fonoaudiologia e Terapia Ocupacional. Brasília, DF. Diário Oficial da União de 10 dez 2001, Seção 1, p. 22.

28. Andrade ÀD, Lemos JC, Dall'ago P. Fisioterapia. In: Brasil. Trajetória dos cursos de graduação na saúde 1991-2004. Org. Haddad AE e col. Brasília, DF: Instituto Nacional de estudos e pesquisa Educacionais Anísio Teixeira. 2006, 209-241.

29. COFFITO. Projeto de Análise e Proposta de Reformulação das Diretrizes Curriculares Nacionais para os Cursos de graduação em Fisioterapia. Brasília, DF. 2016, 36p.

30. Santos SSC. Perfil do egresso de Curso de Enfermagem nas Diretrizes Curriculares Nacionais: uma aproximação. Rev Bras Enf. 2006;59(2):217-221.

31. Kriger L. O diferente é formar generalista. Archives of oral research. 2005;1(4).

32. Abbagnano N. Dicionário de Filosofia. 3ed. São Paulo: Editora Martins Fontes, 1998, 976p.

33. Araujo ESC, Vieira VMO. Práticas docentes na Saúde: contribuições para uma reflexão a partir de Carl Rogers. Psicol. esc. educ. 2013;17(1):97-104.

34. Lima VA. Comunicação e cultura: as idéias de Paulo Freire. 2ed. Rio de Janeiro: Editora Paz e Terra, 1981.

35. Brasil. Lei $n^{\circ} 8.080$ de 19 de setembro de 1990. Dispõe sobre as condições para a promoção, proteção e recuperação da saúde, a organização e o funcionamento dos serviços correspondentes e dá outras providências. Diário oficial da União, Poder Executivo, Brasília, DF, 20 set 1990, p.18055.

36. De Sordi MRL, Bagnato MHS. Subsídios para uma formação profissional crítico-reflexiva na área da saúde: o desafio da virada do século. Rev. Latino-Am. Enfermagem. 1998;6(2):83-88.

37. Perrenoud P. Construir competências é virar as costas aos saberes? Faculdade de Psicologia e Ciências da Educação. Disponível em: http://www.patiopaulista.sp.gov.br/downloads/36/construircompetencias_perrenoud.doc Acesso em: 23 out 2007.

38. Amaro RA. Da qualificação à competência: deslocamento conceitual e individualização do trabalhador. Rev Adm Mackenzie. 2008;9(7):89-111.

39. Pimenta SG, Ghedin E (Orgs.). Professor reflexivo no Brasil: gênese e crítica de um conceito. 4. ed. São Paulo: Cortez, 2006.

40. Fleury MTL, Fleury A. Construindo o Conceito de Competência. Rev Adm Contemp. 2001;Edição Especial:183-196.

41. Delors J. Educação: um tesouro a descobrir. 2ed. São Paulo: Cortez; Brasília, DF: MEC/UNESCO, 2003.

42. Padilha MICS, Borenstein MS. História da enfermagem: ensino, pesquisa e interdisciplinaridade. Esc. Anna Nery Rev. Enferm. 2006;10(3):532-8 